\title{
Natural Convection Heat Transfer between Multiple-Vertical Cylinders
}

\author{
Tetsuya Teramoto ${ }^{1}$, Takehiko Yokomine ${ }^{2}$, Zensaku Kawara ${ }^{2}$, \\ Mitsui Fudosan Co., Ltd. ${ }^{3}$, Japan New Energy Co., Itd. ${ }^{4}$ \\ ${ }^{1}$ Kyoto University, Department of Nuclear engineering \\ Nishikyoku Kyoto University Katsura C3 building d2N02, Kyoto, Japan \\ teramoto.tetsuya.33z@st.kyoto-u.ac.jp; \\ ${ }^{2}$ Kyoto University, Department of Nuclear engineering \\ Nishikyoku Kyoto University Katsura C3 building, Kyoto, Japan
}

\section{Extended Abstract}

Conventional geothermal power generation has problems such as exhaustion of groundwater and clogging of piping by sulfides. To solve these problems, a new geothermal power generation system has been proposed by using co-axial heat exchanger buried in underground geothermal layer. In this system, the working fluid providing heat for power generation is not geothermal fluid, but water which is introduced from the ground to the heat exchanger and then extracted to the ground after heated up by the geothermal energy. Therefore, there is no need to worry about exhaustion of geothermal water and scale due sulfides. We succeeded in the world's first power generation demonstration using this system in Oita prefecture in Japan in 2016. However, it is difficult to accurately predict the power generation output for practical use of this system. In particular, there is no suitable empirical formula to evaluate the natural convection heat transfer of the geothermal fluid that fills the gap between the underground heat exchanger buried in the ground and the formation, and only large-scale numerical calculations have to be relied on. Therefore, we aimed to perform the heat transfer experiment to measure the natural convection heat transfer coefficient which simulate the configuration of underground heat exchanger, geothermal fluid and geothermal layer. The experimental apparatus consists of a heat exchanger inner pipe, a heat exchanger outer pipe, and a simulated layer of a geothermal layer in this order from the centre. The simulated layer of the geothermal layer is pebble bed by using glass beads $12.5 \mathrm{~mm}$ in diameter. A gap is provided between the heat exchanger outer pipe and the simulated layer of the geothermal layer. Water is circulated in the heat exchanger, while the gap and void of pebble bed is filled with oil. The height of test section is $2000 \mathrm{~mm}$. The diameters of inner and outer pipe of heat exchanger are $139.8 \mathrm{~mm}$ and $318.5 \mathrm{~mm}$, respectively. The thickness of the simulated layer is $56 \mathrm{~mm}$ and the width of gap is $114 \mathrm{~mm}$. Electrical heater, heat insulating material, and compensation heater are wound around the outside of the simulated layer, and the heater is divided into 5 in the height direction and can be independently controlled to apply an arbitrary temperature distribution to the simulated layer. Thermocouples are installed in the gap layer, and the temperature at $0,0.5,2.5,5,5,10,35,55,75,104,109,114 \mathrm{~mm}$ from the surface of heat exchanger outer wall for each height $(250,650,1050,1450,1850 \mathrm{~mm})$. The experiments were conducted with a Rayleigh number of geothermal fluid (oil) of gap between $3.7 \times 10^{8}$ and $1.8 \times 10^{9}$. This value corresponds to what is expected of an actual geothermal power plant using this system. Including the cases where the heat flux is constant and not constant, the resultant Nusselt number is as blow,

$$
N u=5.27 * 10^{-6} * R a^{0.821}
$$

where both Nusselt number $\mathrm{Nu}$ and Rayleigh number Ra are based on the gap width as characteristic length. The equation is larger than the value obtained by extrapolating the experimental correlation equation proposed for the vertical annulus by Prasad and Kulacki [1].

\section{References}

[1] V. Prasad, F. A. Kulacki, "Free Convection Heat Transfer in a Liquid-Filled Vertical Annulus," ASME Journal of Heat Transfer, vo1. 107, no. 1985, pp. 596-602. 